\title{
Neonatal outcome of term deliveries in Sri Lanka
}

\author{
Damitha Asanga Gunawardane ${ }^{1}$, Samath D Dharmaratne ${ }^{2}$, Dhammica. S. Rowel ${ }^{3}$
}

${ }^{1}$ Post MD Trainee in Community Medicine; ${ }^{2}$ Professor in Community Medicine and Consultant Community Physician; Department of Community Medicine, Faculty of Medicine, University of Peradeniya. Sri Lanka. ${ }^{3}$ Consultant Community Physician, National Programme Manager, Intranatal and Newborn Care Unit, Family Health Bureau, Ministry of Health, Sri Lanka.

\begin{abstract}
Major proportion (40-70\%) of neonatal mortality is among 'term neonates'. Even though, information on neonatal outcomes of term neonates is scarce. The high volume of term neonatal admissions to neonatal care units signify the importance of studying the neonatal outcomes among term neonates. The aim of this study is to describe the neonatal outcomes, of term neonates following term deliveries (37 completed weeks - 41 completed weeks and 6 days) at Teaching Hospital (TH) Kandy, Sri Lanka. A descriptive cross-sectional study was conducted to describe neonatal outcomes of term neonates before the initial hospital discharge point. A sample of 1,105 neonates, delivered at term were studied during the study period. Mean gestational age at delivery is 38.85 weeks and $41 \%$ of term neonates are delivered before completion of 39 weeks of Period of Amenorrhoea (POA). The mean birth weight of the term neonates is 2925.24 grams. Out of all term neonates, $15.84 \%(n=175)$ were admitted to Neonatal Care Unit (NCU) and $23.3 \%(\mathrm{n}=257)$ had at least one diagnosed neonatal condition. The commonest neonatal condition was bacterial sepsis of newborn $(n=138,12.48 \%)$, followed by neonatal jaundice from other and unspecified causes $(n=84,7.6 \%)$, and respiratory distress of newborn $(n=44,3.94 \%)$. Median hospital stay of term neonates is 3 days. Majority of term neonates admitted to NCU are normal weight term neonates. Nearly one-fourth of term neonates had at least one diagnosed neonatal condition. Prevention and control of infection from the time of birth to the time of discharge from the hospital should be given due attention to reducing bacterial sepsis among term neonates.
\end{abstract}

Keywords: Neonatal outcomes, Term delivery, Term neonates, Neonatal morbidity, Sri Lanka.

\section{Introduction}

Sri Lanka has been able to reduce the under-five mortality rate from 22.2 in 1991 to 9.4 in 2014 and the infant mortality rate from 17.7 in 1991 to 8.0 in 2014 , with a neonatal mortality rate of 5.6 in 2014 , $^{1,2}$

However, neonatal deaths are accounted for more than $80 \%$ of the infant deaths in Sri Lanka. ${ }^{3}$ Therefore, further reduction in infant mortality will only be possible through improving the newborn health. ${ }^{3}$ Major causes of neonatal mortality in Sri Lanka are prematurity, congenital anomalies, birth asphyxia, neonatal sepsis, meconium aspiration syndrome.

When all neonatal deaths are considered $40-70 \%$ of neonatal deaths globally are among term neonates. ${ }^{5-9}$ Even though the neonatal outcomes of preterm neonates have been extensively studied, information on neonatal outcomes of term neonates is scarce. ${ }^{10}$ The high volume of term neonatal admissions to neonatal care units further signifies the importance of studying the neonatal outcomes among term neonates. ${ }^{11}$

A neonate born at term is a neonate born at term gestation. Conventionally a term gestation is defined as the period of gestation from 37 completed weeks (259 days) up to and including 41 completed weeks and 6 days (293 days). ${ }^{12}$

"Globally the ability to evaluate trends and risk factors across the spectrum of term gestation is limited for mortality and hardly available for morbidity". ${ }^{10}$ Therefore, it is important to study the neonatal outcomes, including both favorable as well as adverse outcomes and their as-

\section{Practice Points}

- Neonatal deaths are accounted for more than $80 \%$ of the infant deaths in Sri Lanka.

- Out of all term neonates, $15.84 \%(n=175)$ were admitted to NCU.

- Nearly one-fourth of term neonates had at least one diagnosed neonatal condition.

- Commonest neonatal condition was bacterial sepsis of newborn $(n=138,12.48 \%)$, followed by neonatal jaundice from other and unspecified causes $(n=84,7.6 \%)$, and respiratory distress of newborn $(n=44,3.94 \%)$.

- Prevention and control of infection from the time of birth to the time of discharge from the hospital should be given due attention to reducing bacterial sepsis among term neonates.

sociated factors to identify the areas of maternal and neonatal care, which will need specific focus to prevent adverse neonatal outcomes among term neonates. On the other hand, delivery at 40 or 41 weeks of gestation had a higher risk of birth weight greater than 4500 grams, neonatal injury and meconium aspiration whereas delivery at 37 or 38 weeks had a higher risk of hyaline membrane disease but lower risk of meconium aspiration. ${ }^{13}$

It is observed that neonatal outcome in term neonates differ in different countries. It is shown that the shape of the distribution of gestational age at birth, among

Correspondence: Dr. Damitha Asanga Gunawardane, 17, Hansa Sevana, Sooriyagoda, Muruthalawa. Sri Lanka. E-mail: damithagunawardane@gmail.com. 
term neonates varied from country to country. In some countries, there was a sharp cutoff in deliveries at 40 weeks, while other countries this occurred at 41 weeks based on their obstetric practices. ${ }^{14}$

A study conducted by Telatar et $a l .{ }^{15}$ at Turkey reported mean birth weight, height and head circumference of term neonates as 3334g (SD 494), 48.3cm (SD2.2) and $34.4 \mathrm{~cm}$ (SD1.3) respectively. The study done among 2215 term neonates in Sri Lanka found mean birth weight, mean length and mean head circumference at birth were $2920 \mathrm{~g}$ (SD 400), 49.1(SD 2) and $33.4 \mathrm{~cm}$ (SD 1.1) respectively. ${ }^{16}$ Interestingly Perera et al. ${ }^{16}$ found that growth parameters continued to increase progressively up to 41 weeks. Similar finding has been reported by another Sri Lankan study. ${ }^{17}$

Having a normal birth weight newborn at term is generally expected to lead to an optimum outcome for the newborn. Some authors have studied the outcome of the newborns born at term with a normal birth weight. Olusanya $^{18}$ described the neonatal outcomes among term newborns with normal birth weight. Out of 2687 term newborns with normal birth weight studied, 242 $(9 \%)$ were admitted to the special care baby unit, which accounts for $53.6 \%$ of all special care baby unit admissions. Further Olusanya ${ }^{18}$ reported the following neonatal morbidity conditions in the sample; Neonatal sepsis (2.5\%), Hyperbilirubinemia (1.9), congenital defects (0.5\%) and 5-minute Apgar score 0-6 (24.9\%). Compared to this ${ }^{18}$ study higher percentage of morbidity was shown in another study (Kerala, India) where $16.3 \%$ $(n=1094)$ of term neonates had some kind of neonatal morbidity, which includes need for resuscitation (1.7\%), need for respiratory support $(3.4 \%)$, hypoglycaemia $(2.2 \%)$, hyperbilirubinemia $(10.4 \%)$, sepsis $(0.9 \%)$ and need for intravenous fluid $(2 \%) .{ }^{19}$ The percentage of term neonates affected with neonatal conditions such as hyperbilirubinaemia and asphyxia were markedly different in the two studies as the previous sample had only normal weight babies. Similar study conducted by the Leone et al. ${ }^{20}$ at five hospitals in Switzerland to investigate the short-term morbidity among late preterm and term neonates, reported that the risk of develop at least one complication as $9.3 \%$ among term neonates $(\mathrm{n}=1686)$, which consisted of respiratory distress $(4.6 \%)$, hyperbilirubinaemia $(3.4 \%)$ and hypothermia $(0.6 \%)$. The average duration of hospitalization was 5.2 days for term infants.

Amir et $a l .^{21}$ highlighted that the data on mortality of full-term infants are scarce and the neonatal mortality rate is disproportionately influenced by preterm infants and does not reflect the rate in full-term neonates. A retrospective study conducted by Amir et al. ${ }^{21}$ using data from 44703 term births (for a period of 6 years), found a mortality rate of 0.69 per 1000 live births among term neonates. The main cause of death was congenital anomalies (64.5\%), specifically cardiac anomalies. Other causes were chromosomal anomalies or syndromes $(12.9 \%)$, labour complications (12.9\%), infections $(3.2 \%)$, congenital diseases $(3.2 \%)$ and metabolic disorders $(3.2 \%)$.

Even though the risk of adverse neonatal outcomes of births at term are less compared to pre-term and postterm births, term neonates are responsible for a significant proportion of newborns requiring intensive or spe- cial newborn care. Out of many reasons for the above phenomenon, problems occurring at intrapartum care, infection, birth asphyxia and suboptimal obstetric care are some of them. ${ }^{18}$ Therefore, the pattern of outcomes and the knowledge of the risk factors associated with those outcomes are important in guiding preventive strategies and clinical decision-making.

Almost $90 \%$ of the babies are born at term in Sri Lanka. ${ }^{22}$ Therefore, it would be very useful to conduct a study, which will deal with the problems of the term neonates, maternal risk factors for them and cost for adverse neonatal outcomes, which will signify the importance of prevention and management of adverse neonatal outcomes among term neonates. Based on comprehensive literature review it was found that none of the above aspects of term neonates has been studied in Sri Lanka. Therefore it important to study above aspects with regard to Sri Lankan context.

Therefore, the aim of this study is to describe the neonatal outcomes following term deliveries at Teaching Hospital Kandy, Sri Lanka.

\section{Materials and methods}

The study was conducted as a descriptive crosssectional study at Teaching Hospital Kandy during the period of 3 months from 26th of February to 20th of May 2015. Following term neonates were excluded from the study, Neonates of mothers with uncertain Last Menstrual period (LMP), Neonates of mothers who did not have an Ultra Sound Scan (USS) before the completion of 24 weeks of gestation, Neonates of mothers whose USS Expected Date of Delivery (EDD) is different from EDD calculated by the LMP more than 14 days and Neonates who were transferred out from the hospital. First, three exclusion criterions were used in this study were to minimize the chance of pre-term and postterm neonates getting into the study group.

Due to non-availability of a reliable estimate to be used in this setting, with the assumption of $50 \%$ prevalence of outcomes and to obtain a precision of 3\% at $95 \%$ confidence level 1068 study subjects were needed. ${ }^{23}$

Data collection was done at postnatal wards by the 3 female pre-intern doctors using intervieweradministered questionnaire. Mothers were interviewed by data collectors in their stable situation after the delivery in post-natal ward. The purpose of the study was clearly explained to them. Those who gave consent to take part, a face to face interview was taken and antenatal card and delivery records in mother's Bed Head Ticket (BHT) were reviewed to collect the necessary information. An interview took about 15 to 20 minutes. In total 1105 neonates with 4 twin deliveries, were recruited for the study.

Delivery occurred during the period of gestation from 37 completed weeks (259days) up to and including 41 completed weeks and 6 days (293days), based on the gestational age at delivery is defined as a term delivery. Gestational age at delivery was taken as decided by an Obstetrician based on the LMP, USS and other antenatal factors.

Data were extracted from each selected newborn mother 
pair identified by the hospital BHT number and study number given in consecutive sequence until the sample size was full filled. The study was limited to the initial point of discharge and the outcomes beyond that point were not be considered. At the end of every 24 hours until the time of initial discharge or death, neonates were followed up prospectively.

Data entry was done by using Microsoft Access 2013. Data analysis was performed by using SPSS software. Data transferring was done through the Microsoft Excel. Continuous variables were summarized with means and standard deviations or medians and interquartile range as appropriate. Percentages were used to describe categorical variables.

Ethical clearance was obtained from the Ethical Review Committee of Faculty of Medicine Colombo.

\section{Results}

In this study, neonatal outcomes were measured using gestational age at birth, birth weight, Apgar score at 1, 5 and 10 minutes, Neonatal Care Unit admission, and morbidity. Since there was only one death among the term neonates recruited for this study mortality will not be presented or discussed as a separate topic in this paper.

The mean gestational age at delivery in this sample of term neonates was 38.85 weeks with a median of 39 weeks. About one-third of babies $(n=398,36 \%)$ were born at 40 and 41 weeks. Forty-one percent of neonates $(n=456)$ was born at 37 or 38 weeks (Table 1$)$.

Birth weight of term neonates ranged from $1500 \mathrm{~g}$ to $4850 \mathrm{~g}($ Median $=2900 \mathrm{~g})$. Only 13.8 percent $(\mathrm{n}=152)$ of

Table 1: Distribution of term neonates by gestational age and weight at birth

\begin{tabular}{|l|l|}
\hline Neonatal Characteristic & Frequency (\%) \\
\hline Gestational age by weeks (Completed weeks) \\
\hline 37 & $160(14.5 \%)$ \\
\hline 38 & $296(26.8)$ \\
\hline 39 & $251(22.7)$ \\
\hline 40 & $344(31.1)$ \\
\hline 41 & $54(4.9)$ \\
\hline \multicolumn{2}{|c|}{ Mean \pm SD: $38.85 \pm 1.15$} \\
\hline Birth weight categories & $19(1.7)$ \\
\hline$<2000 \mathrm{~g}$ & $133(12)$ \\
\hline $2000-2499 \mathrm{~g}$ & $471(42.6)$ \\
\hline $2500-2999 \mathrm{~g}$ & $362(32.8)$ \\
\hline $3000-3499 \mathrm{~g}$ & $106(9.6)$ \\
\hline $3500-3999$ & $14(1.3)$ \\
\hline 4000 or more & Mean \pm SD:2925.24 2455.63 \\
\hline \multicolumn{2}{|c|}{} \\
\hline
\end{tabular}

newborns had a birth weight less than $2500 \mathrm{~g}$. The proportion of newborns weighing $3500 \mathrm{~g}$ or over was 10.9 percent $(n=120)$. The distribution of Birth weights of term neonates is detailed in Table 1.

Mean length of the newborns was $52.09 \mathrm{~cm}$ with a range of $33 \mathrm{~cm}$ to $62 \mathrm{~cm}$. Head circumference was within the range of $26 \mathrm{~cm}$ to $54 \mathrm{~cm}$ with a mean of $33.18 \mathrm{~cm}$. A number of neonates without recorded length and head circumference were 8 and 9 respectively.

The Apgar score at one minute after birth ranged from 1 to 10 (Median10). One percent of term neonates $(n=$ 12) had 1 minute Apgar score less than 4. Proportion of neonates with Apgar score less than 7 was (48) $4.4 \%$ at 1 minute, $1.7 \%(n=19) 5$ minutes and $0.5 \%$ $(\mathrm{n}=5)$ at 10 minutes.

With regard to length of stay of term neonates in the hospital, the median length of hospital stay was 3 days. Only $37 \%(n=412)$ of term neonate had been discharged within less than 2 inpatient days. More than $80 \%$ of term neonates including the neonates born by LSCS had been discharged by 5 days of hospital stay. Sixty-eight percent of neonates who delivered through normal vaginal delivery had been discharged within 2 days. Among term neonates who delivered through emergency $\mathrm{CS}, 36 \%$ had 6 or more days of hospital stay (Table 2).

Out of all term neonates in the study sample $15.84 \%$ $(\mathrm{n}=175)$ neonates required admission to NCU. More than $70 \%$ of neonates admitted to NCU were normal weight babies and the majority $(66.9 \%)$ were boys. Details are given in Table 3.

Out of 1105 neonates included in the study, 23.3\% $(n=257)$ had at least one diagnosed neonatal condition. Commonest neonatal condition was bacterial sepsis of newborn $(n=138,12.48 \%)$, followed by neonatal jaundice from other and unspecified causes $(\mathrm{n}=84,7.6 \%)$ and respiratory distress of newborn $(\mathrm{n}=44,3.94 \%)$. Out of neonates with at least one neonatal condition $(n=257), 53.7 \%$ had bacterial sepsis of newborn and $32.7 \%$ had neonatal jaundice from other and unspecified causes (Table 4).

\section{Discussion}

In the present study 'selection bias 'could have occurred through non-participation. But the participation rate was very high in this study and only 14 mothers $(1.25 \%)$ did not give their consent for the study. Therefore 'selection bias' in terms of nonparticipation in this study can be considered as negligible.

Mean gestational age at delivery was 38.85 weeks and

Table 2: Association between mode of delivery and length of hospital stay

\begin{tabular}{|l|c|c|c|c|c|}
\hline \multirow{2}{*}{ Mode of Delivery } & \multicolumn{5}{|c|}{ Length of Hospital Stay } \\
\cline { 2 - 6 } & $\mathbf{1}$ & $\mathbf{2}$ & $\mathbf{3 - 5}$ & $\mathbf{6 +}$ & Total \\
\cline { 2 - 6 } & $\mathrm{n}(\%)$ & $\mathrm{n}(\%)$ & $\mathrm{n}(\%)$ & $\mathrm{n}(\%)$ & $\mathrm{n}(\%)$ \\
\hline Normal Vaginal Delivery & $237(39.3 \%)$ & $173(28.7 \%)$ & $111(18.4 \%)$ & $82(13.6 \%)$ & $603(100 \%)$ \\
\hline Instrumental Delivery & $0(0)$ & $2(18.2 \%)$ & $7(63.6 \%)$ & $2(18.2 \%)$ & $11(100 \%)$ \\
\hline CS-Emergency & $0(0)$ & $0(0)$ & $128(64 \%)$ & $72(36 \%)$ & $200(100 \%)$ \\
\hline CS-Elective & $0(0)$ & $0(0)$ & $241(82.8 \%)$ & $50(17.2 \%)$ & $291(100 \%)$ \\
\hline Total & $237(21.4 \%)$ & $175(15.8 \%)$ & $487(44.1 \%)$ & $206(18.6 \%)$ & $1105(100 \%)$ \\
\hline
\end{tabular}

South East Asia Journal of Public Health 2017;7(2):34-39 
Table 3: Distribution of Term Neonates Admitted to the NCU by Neonatal Characteristics

\begin{tabular}{|c|c|}
\hline Characteristic & Frequency (\%) \\
\hline \multicolumn{2}{|l|}{ Gestational age at birth } \\
\hline 37 & $43(24.6 \%)$ \\
\hline 38 & $43(24.6 \%)$ \\
\hline 39 & $31(17.7 \%)$ \\
\hline 40 & $56(32 \%)$ \\
\hline 41 & $2(11 \%)$ \\
\hline \multicolumn{2}{|c|}{ Age at Admission to NCU (Days) } \\
\hline 1 & $120(68.6 \%)$ \\
\hline 2 & $22(12.6 \%)$ \\
\hline 3 & $17(9.7 \%)$ \\
\hline 4 & $11(6.3 \%)$ \\
\hline 5 & $4(2.3 \%)$ \\
\hline 6 & $1(6 \%)$ \\
\hline \multicolumn{2}{|l|}{$\operatorname{Sex}$} \\
\hline Male & $117(66.9 \%)$ \\
\hline Female & $58(33.1 \%)$ \\
\hline \multicolumn{2}{|l|}{ Birth weight (Grams) } \\
\hline$<2000$ & $14(8 \%)$ \\
\hline $2000-2499$ & $35(20 \%)$ \\
\hline $2500-2999$ & $50(28.6 \%)$ \\
\hline $3000-3499$ & $52(29.7 \%)$ \\
\hline $3500-3999$ & $19(10.9 \%)$ \\
\hline 4000 or more & $5(2.9 \%)$ \\
\hline \multicolumn{2}{|l|}{ Indication for admission } \\
\hline Tachypnoea /Grunting & $87(49.71 \%)$ \\
\hline Jaundice & $42(24 \%)$ \\
\hline Hypoglycaemia & $14(8 \%)$ \\
\hline Other & $32(18.29 \%)$ \\
\hline Total & $175(100 \%)$ \\
\hline
\end{tabular}

the majority $(31.1 \%)$ of term neonates were delivered at 40 weeks of gestation. Out of all, $41.26 \%$ delivered before completion of 39 weeks. Perera et al. ${ }^{16}$ also reported similar finding in their study where $42 \%$ of term neonates were delivered before completion of 39 weeks. But the study conducted in maternity institutions in Gampaha district, the majority $(28.33 \%)$ of deliveries occurred at 39 weeks of gestation.

The gestational age at birth is noted to be different from country to country. As reported in one study done in Europe, which included 5 countries, ${ }^{14}$ demonstrated that the shape of gestational age distribution peeks at 40 weeks but only $20.32 \%$ deliveries occurred before completing the 39 weeks of gestation. This is dependent on the obstetric practices of the country and it can be noted that in our study sample $56.6 \%$ of babies were delivered by caesarean section.

The mean birth weight of the term neonates in the present study was 2925.24 grams which was perfectly tallied with 2930 grams reported by the Perera et al. ${ }^{16}$ In the present study $13.7 \%(\mathrm{n}=152)$, had a birth weight less than $2500 \mathrm{~g}$ and $10.9 \%(\mathrm{n}=120)$ had birth weight either $3500 \mathrm{~g}$ or more. This was consistent with findings of the Perera et al. ${ }^{16}$ study, where they have reported their $10^{\text {th }}$ and $90^{\text {th }}$ percentiles as $2420 \mathrm{~g}$ and $3470 \mathrm{~g}$ respectively. As this is a sample of term neonates, as expected the percentage of low birth weight is less than the percentage of low birth weight as found in the Demographic Health Survey (2007) for the Kandy District after considering all the live births. ${ }^{2}$

Mean length of the term neonates was $52.09 \mathrm{~cm}$ with a range of $33 \mathrm{~cm}$ to $62 \mathrm{~cm}$. Head circumference was varied from $26 \mathrm{~cm}$ to $54 \mathrm{~cm}$ with a mean of $33.18 \mathrm{~cm}$

Table 4: Distribution of Term Neonates Diagnosed with a Neonatal Condition According to ICD 10 Code

\begin{tabular}{|l|l|c|}
\hline ICD 10 Code & \multicolumn{1}{|c|}{ Condition } & $\mathbf{n}\left(\mathbf{\%}^{*}\right)$ \\
\hline & Total & 257 \\
\hline P36 & Bacterial sepsis of newborn & $138(12.5)$ \\
\hline P59 & Neonatal jaundice from other and unspecified causes & $84(7.6)$ \\
\hline P22 & Respiratory distress of newborn & $44(3.9)$ \\
\hline Z29 & Need for other prophylactic measures & $41(3.7)$ \\
\hline P29 & Cardiovascular disorders originating in the perinatal period & $29(2.6)$ \\
\hline P05 & Slow fetal growth and fetal malnutrition & $26(2.4)$ \\
\hline P55 & Haemolytic disease of fetus and newborn & $19(1.7)$ \\
\hline P 21 & Birth asphyxia & $18(1.7)$ \\
\hline P70 & Transitory disorders of carbohydrate metabolism specific to fetus and newborn & $10(<1.0)$ \\
\hline P23 & Congenital pneumonia & $8(<1.0)$ \\
\hline P12 & Birth injury to scalp & $7(<1.0)$ \\
\hline P24 & Neonatal aspiration syndromes & $7(<1.0)$ \\
\hline Q21 & Congenital malformations of cardiac septa & $6(<1.0)$ \\
\hline P61 & Other perinatal haematological disorders & $5(<1.0)$ \\
\hline P90 & Convulsions of newborn & $4(<1.0)$ \\
\hline Q90 & Down syndrome & $3(<1.0)$ \\
\hline P91 & Other disturbances of cerebral status of newborn & $2(<1.0)$ \\
\hline Q02 & Microcephaly & $2(<1.0)$ \\
\hline Q25 & Congenital malformations of great arteries & $2(<1.0)$ \\
\hline Q37 & Cleft palate with cleft lip & $2(<1.0)$ \\
\hline Z3.0 & Medical observation and evaluation for suspected diseases and conditions & $2(<1.0)$ \\
\hline Q01 & Encephalocele & $1(<1.0)$ \\
\hline Q03 & Congenital hydrocephalus & $1(<1.0)$ \\
\hline Q42 & Congenital absence, atresia and stenosis of large intestine & $1(<1.0)$ \\
\hline *Percentage out of all newborns in the study (n=1105) & \\
\hline
\end{tabular}


in the present study. Perera et al. ${ }^{16}$ study reported $49.1 \mathrm{~cm}$ and $33.6 \mathrm{~cm}$ as mean length and head circumference respectively. The difference in length could be either due to a systematic error occurred in the length measurement or it could be due to constitutional factors since these two studies were conducted in two different geographical areas in Sri Lanka.

According to International Classification of Diseases (ICD)-10,25 Apgar score is a supportive evidence to diagnose birth asphyxia but it cannot be diagnosed only based on the Apgar score. According to the classification, 1-minute Apgar score of 0-3 is suggestive of severe birth asphyxia and Asphyxia with 1-minute Apgar score 4-7 is suggestive of mild and moderate birth asphyxia. In the present study, 4.4 percent and 1.7 percent had Apgar score less than 7 at 1 minute and 5 minutes respectively. Finding on 5 minutes Apgar score less than 7 is compatible with the 1.49 percent in the Tracy et $a l .{ }^{26}$ study.

Length of Hospital stay had been measured inpatient days. The patient day has been defined as a day during which a patient stays overnight in a hospital. National policy on hospital discharge of a term neonate with normal birth weight is to discharge after 24 hours of birth following normal vaginal delivery. Sixty-eight percent of neonates who delivered through normal vaginal delivery had been discharged within 2 days. Median hospital stay of 3 days found in this study was mainly due to higher caesarian section rate $(44.4 \%)$ among the study group. This was much less than the 5.2 days of hospital stay for term neonates reported by Leone et $a l .^{20}$

Out of all term neonates in the study, $15.84 \%(n=175)$ on neonates required Neonatal Care Unit admission. This was higher than the $9 \% \quad(n=242)$ of Olusanya study $^{18}$ and $14.4 \% \quad(n=1671)$ of Alkiaat et al. ${ }^{27}$ study. The majority of neonates who were admitted to an NCU were admitted during their first day of life $(n=120$, $68.6 \%$ ) and the median age at admission was 1 day, in the present study. This is consistent with the finding of Olusanya study. ${ }^{18}$

Two thirds $(66.9 \%)$ of neonates admitted to NCU were male neonates. Male predominance among NCU admissions was noted in all most all the studies referred. ${ }^{18,27,28}$ Further, $62 \%$ of all neonates admitted had a birth weight of $2500 \mathrm{~g}$ or more. This indicates that the majority of term neonates admitted to NCU was normal weight term babies.

Out of 1105 neonates included in the study 23.3 $(n=257)$, percent had at least one diagnosed neonatal condition. This was much higher than the same percentages reported by Leone et al. ${ }^{20}$ and Wagh \& Jain ${ }^{19}$ which were $9.3 \%$ and $16.3 \%$.

Commonest neonatal condition was bacterial sepsis of newborn $(\mathrm{n}=138,12.48 \%)$, followed by neonatal jaundice from other and unspecified causes $(n=84,7.6 \%)$ and respiratory distress of newborn $(n=44,3.94 \%)$. Even though the proportions were less, similar morbidity pattern had been reported by the Olusanya. ${ }^{18}$ Where Neonatal sepsis (2.5\%), Hyperbilirubinemia (1.9), and congenital defects $(0.5 \%)$ were the leading causes of neonatal conditions diagnosed among term neonates.
Somewhat different morbidity pattern had been reported by the Leone et $a l .{ }^{20}$ where respiratory distress (4.6) was the leading cause of morbidity among term neonates, followed by the hyperbilirubinaemia (3.4\%) and hypothermia $(0.6 \%)$.

High level of bacterial sepsis needs to be addressed by improving the aseptic practices from the time of birth to the time of discharge from the hospital.

In the present study, only one neonate died due to meconium aspiration, therefore, the mortality was at a very low level among the present study group. This was consistent with findings of a study done by Amir et al., ${ }^{21}$ where he reported a mortality rate of 0.69 per 1000 live births. Further, he reported congenital anomalies $(64.5 \%)$ as the major cause of death, followed by labour complication $(12.9 \%)$ and infection $(3.2 \%)$.

\section{Conclusion}

Median hospital stay of term neonates was 3 days. The proportion of term neonates admitted to the neonatal care unit was 15.84. Majority of term neonates admitted to NCU are normal weight term neonates. Nearly onefourth of term neonates had at least one diagnosed neonatal condition. The commonest neonatal condition is bacterial sepsis of newborn. Prevention and control of infection from the time of birth to the time of discharge from the hospital should be given due attention to reducing bacterial sepsis among term neonates.

\section{Competing interest}

The author(s) declared no potential conflicts of interest with respect to the research, authorship, and/or publication of this article.

\section{Acknowledgement}

We thank all the staff members of the Teaching hospital, Kandy for the support given by them to conduct this study.

\section{References}

1. Department of Census and Statistics. 2015; http://www.statistics.gov.lk/ (accessed Jan 2015)

2. Family Health Bureau. Annual Report. Sri Lanka.: Ministry of Health;2015.

3. United Nations in Sri Lanka. Millennium Development Goals: Country Report Colombo, Sri Lanka2014.

4. Family Health Bureau. National Strategic Plan Maternal And Newborn Health. Ministry of Health Sri Lanka;2011.

5. Baqui AH, Darmstadt G, Williams E, Kumar V, Kiran T, Panwar D, et al. Rates, timing and causes of neonatal deaths in rural India: implications for neonatal health programmes. Bull World Health Organ. 2006;84(9):706-713.

6. Oza S, Lawn JE, Hogan DR, Mathers C, Cousens SN. Neonatal cause-of-death estimates for the early and late neonatal periods for 194 countries: 2000-2013. Bull World Health Organ. 2015;93 (1):19-28 
7. Baqui AH, Rosen HE, Lee ACC, Applegate JA, El Arifeen S, Rahman SM, et al. Preterm birth and neonatal mortality in a rural Bangladeshi cohort: implications for health programs. J Perinatol. 2013;33(12):977-981.

8. Hidayah D, Hafidh Y. Risk factors for neonatal mortality at Moewardi Hospital, Surakarta. Paediatr Indones. 2014;54(4):219.

9. Jehan I. Neonatal mortality, risk factors and causes: a prospective population-based cohort study in urban Pakistan. Bull World Health Organ. 2009;87(2):130-138.

10. Spong CY. Defining "term" pregnancy: recommendations from the Defining "Term" Pregnancy Workgroup. JAMA. 2013;309(23):2445-2446.

11. Schiariti V, Klassen A, Hoube J, Synnes A, Lisonkova S, Lee S. Perinatal characteristics and parents' perspective of health status of NICU graduates born at term. J Perinatol. 2008;28 (5):368-376.

12. Campbell S, Lees C. Obstetrics by ten teachers. London: Arnold; 2000.

13. Cheng YW, Nicholson JM, Nakagawa S, Bruckner TA, Washington AE, Caughey AB. Perinatal outcomes in low-risk term pregnancies: do they differ by week of gestation? Am J Obstet Gynecol. 2008;199(4):370 e371-377.

14. Zeitlin J, Blondel B, Alexander S, Bréart G, Wildman K, Barros H, et al. Variation in rates of postterm birth in Europe: Reality or artefact? BJOG. 2007;114(9):1097-1103.

15. Telatar B, Comert S, Vitrinel a, Erginöz E. Anthropometric measurements of term neonates from a state hospital in Turkey. East Mediterr Health J. 2009;15(6):1412-1419.

16. Perera $\mathrm{P}$, Ranathunga $\mathrm{N}$, Warnakulasuriya $\mathrm{T}$, Wickremasinghe R, Fernando M. Growth parameters at birth of babies born in Gampaha district, Sri Lanka and factors influencing them. WHO South East Asia J Public Health. 2013;2(1):5761.

17. Nanayakkara D. Anthropometric measurements of Sri Lankan newborns. Ceylon Med J. 1998;41 (1):1-6.
18. Olusanya BO. Full-term newborns with normal birth weight requiring special care in a resourceconstrained setting. Pan Afr Med J. 2013;15:110 .

19. Wagh AS, Jain N. Comparison of neonatal morbidities of late preterm with term born babies. . $J$ Pharm Biomed Sci. 2012;15(15):1-6.

20. Leone A, Ersfeld P, Adams M, Schiffer PM, Bucher HU, Arlettaz R. Neonatal morbidity in singleton late preterm infants compared with full -term infants. A cta Paediatr. 2012;101(1):e6-10.

21. Amir A, Merlob P, Linder N, Sirota L, Klinger G. Mortality of full-term infants during the first month of life in a tertiary care hospital. J Perinatol. 2007;27(10):620-622.

22. Ruwanpathirana T, Senanayake H, Fernando D. Development of birth weight for gestational age charts in a Sri Lankan setting - methodological issues. WHO South East A sia J Public Health 2013;2(1):47-47.

23. Chadha V. Sample size determination in health studies. NTI bulletin. 2006;42(3\&4):55-62.

24. Department of Census Statistics. Sri Lanka Demographic and Health Survey 2006/2007. Colombo, Sri Lanka 2008.

25. World Health Organization. International Classification of Diseases (ICD). 2015; http:// apps.who.int/classifications/icd10/browse/2015/ en\#/P21 (accessed May 2014)

26. Tracy SK, Tracy MB, Sullivan E. Admission of term infants to neonatal intensive care: a population-based study. Birth. 2007;34(4):301-307.

27. Alkiaat A, Hutchinson M, Jacques A, Sharp MJ, Dickinson JE. Evaluation of the frequency and obstetric risk factors associated with term neonatal admissions to special care units. Aust $N Z J$ Obstet Gynaecol. 2013;53(3):277-282.

28. Evers A, van Leeuwen J, Kwee A, Brouwers H, Koopman-Esseboom C, Nikkels $\mathrm{P}$, et al. [Mortality and morbidity among full-term neonates in a neonatal intensive care unit in the Utrecht region, the Netherlands]. Ned Tijdschr Geneeskd. 2010;154:A118-A118. 